\title{
The phospholamban p.Arg14del founder mutation in Dutch patients with arrhythmogenic cardiomyopathy
}

\author{
J. F. van der Heijden • R. J. Hassink
}

Published online: 18 April 2013

(C) The Author(s) 2013. This article is published with open access at Springerlink.com

Arrhythmogenic right ventricular dysplasia/cardiomyopathy $(\mathrm{ARVD} / \mathrm{C})$ is considered a hereditary cardiac disease, characterised by ventricular arrhythmias with left bundle branch block morphology, fibro-fatty replacement of cardiomyocytes and predominantly affecting the right ventricle [1, 2]. Recently, arrhythmogenic cardiomyopathy (AC) was suggested as the preferred terminology [3]. The most important considerations for this are that patients and families with ventricular arrhythmia and similar ARVD/C histopathological changes in the left ventricle have been recognised and described as left-dominant arrhythmogenic cardiomyopathy [4]. Mutations in desmosomal genes are associated with both ARVD/C and left-dominant arrhythmogenic cardiomyopathy and at the molecular level both ventricles and the interventricular septum are similarly affected $[5,6]$.

Classically AC is considered a disease of the desmosomes. Desmosomes are protein complexes located in the intercalated disk, important for mechanical integrity. For example, in approximately $60 \%$ of Dutch AC patients a pathogenic desmosomal mutation is found, predominantly in the PKP2 gene [7]. Non-desmosomal genes have also been identified in families with phenotypical AC, for example TMEM43 [8]. Another mutation in a non-desmosomal gene is the p.Arg14del mutation in the phospholamban $(P L N)$ gene. Phospholamban is involved in calcium homeostasis in the sacroplasmatic reticulum of the cardiac muscle cell [9]. Mutation carriers are phenotypically characterised

J. F. van der Heijden $(\bowtie) \cdot$ R. J. Hassink

Department of Cardiology, University Medical Center Utrecht,

Huispostnummer: E03.511, Heidelberglaan 100, P.O. Box 85500,

3508 GA Utrecht, the Netherlands

e-mail: j.f.vanderheijden-2@umcutrecht.nl by low-voltage electrocardiograms, ventricular arrhythmias, and contractile dysfunction involving both ventricles.

Van der Zwaag et al. found that the PLN mutation was especially prevalent in the Netherlands, both in dilated cardiomyopathy (13\%) as well as in AC (12\%) [10]. This was a surprising finding because in other cohorts the prevalence of the PLN p.Arg14del mutation was found to be very low, between $0.08 \%$ and $0.38 \%$ [11]. In this issue of the Journal, Van der Zwaag et al. describe the origin of the PLN p.Arg14del founder mutation in the Netherlands [11]. This paper fits nicely in a series of articles started in 2009 on founder mutations in the Netherlands in different cardiomyopathies [12]. Founder mutations are mutations that emerged in a population many generations ago and have subsequently spread among following generations.

In the study by Van der Zwaag et al. [11]. a large number of PLN p.Arg14del founder mutation carriers (probands and family members) were identified, in total 459 individuals. The authors analysed the origin of the PLN founder mutation first by haplotype analysis revealing that the mutation is estimated to be between 575 and 825 years old. Subsequently, in order to approximate the geographical origin of the PLN mutation the places of birth of the grandparents of the probands were plotted on a postal code map of the Netherlands, revealing that the majority of the grandparents came from the eastern part of the Dutch province of Friesland. The grandparents included in this study were born roughly between 1900 and 1925 , i.e. approximately 75 to 100 years ago. At least six centuries of history are not accounted for, while in this time a lot happened. A quick search on the internet reminds us of the many wars the Dutch (including the 'Friezen') had with different enemies (e.g. Swedish, Spanish and Germans). The haplotype in the German family was the same as the haplotype found in the Dutch families, 
rising the possibility that the PLN founder mutation was introduced in Friesland by a German soldier, who possibly found a new love in Friesland. Also, due to migration, the residential area of the 'Friezen' around 1300 ran from the province of Noord-Holland up to Denmark. Therefore, it is still not sure that the origin of the mutation is in Friesland. A more detailed study of the migration in Friesland is needed to elucidate the exact place of origin of the PLN mutation; however, this is probably impossible, without the necessary registries.

The authors subsequently studied the prevalence of the PLN p.Arg14del mutation in the PREVENT cohort, a large population-based cohort from the city of Groningen, in the north of the Netherlands $(N=8267)$. In this cohort six heterozygous PLN mutation carriers were found $(0.07 \%)$. As migration in the Netherlands has been very limited, as stated by the authors, the PREVENT cohort is possibly not the best cohort to test the true prevalence of the mutation in the Netherlands. Possibly the prevalence of the PLN founder mutation can be more accurately determined in other Dutch cohorts, not specifically including patients from the north of the country (e.g. ERGO, Rotterdam or SMART study, Utrecht).

Of particular interest is the great difference in clinical expression in mutation carriers in the different families as shown by the family presented by the authors. This phenomenon is present in many different cardiomyopathies (e.g. hypertrophic cardiomyopathy) and primary electric cardiac diseases (e.g. long-QT syndrome). Different possible answers are the presence of polymorphisms influencing the calcium handling in the cardiac myocyte or related genes. Recently, the down-regulation of the cardiac sodium channel was found to be important in arrhythmogenesis in plakophylin-2 haploinsufficient mice ${ }^{13}$ and is possibly a predictor for SCD in patients with $\mathrm{AC}$, making SCN5A another possible modulating gene, for example. Furthermore, differences between family members in the susceptibility for fibrosis in the heart could be of importance. Finally, there might be regions in the Netherlands with specific 'environmental influences' that make people more susceptible for developing a more severe phenotype.

As mentioned before, in the PREVENT cohort six carriers of the PLN mutation were found and one of them developed heart failure within 10 years of follow-up $(17 \%)$. The question is whether it is mandatory to identify all carriers of the PLN mutation to be able to screen these individuals for risk factors for sudden cardiac death and/or heart failure. As the authors already state the PHORECAST study is an important tool to investigate the questions about risk stratification for sudden cardiac death and development of heart failure, consequently these findings should give rise to treatment strategies to prevent these severe complications.

In conclusion, the PLN p.Arg14del founder mutation appears to originate from the north of Friesland. In the near future the goal should be to identify all carriers of the PLN p.Arg14del mutation to be able to prevent SCD and possibly treat asymptomatic carriers to prevent progression to disease.

Funding None.

Conflict of interests None declared.

Open Access This article is distributed under the terms of the Creative Commons Attribution License which permits any use, distribution, and reproduction in any medium, provided the original author(s) and the source are credited.

\section{References}

1. Marcus FI, Fontaine GH, Guiraudon G, et al. Right ventricular dysplasia: a report of 24 adult cases. Circulation. 1982;65:384-98.

2. Basso C, Thiene G, Corrado D, et al. Arrhythmogenic right ventricular cardiomyopathy. Dysplasia, dystrophy, or myocarditis? Circulation. 1996;94:983-91.

3. Ackerman MJ, Priori SG, Willems S, et al. HRS/EHRA expert consensus statement on the state of genetic testing for the channelopathies and cardiomyopathies this document was developed as a partnership between the Heart Rhythm Society (HRS) and the European Heart Rhythm Association (EHRA). Hear Rhythm. 2011;8:1308-39.

4. Sen-Chowdhry S, Syrris P, Prasad SK, et al. Left-dominant arrhythmogenic cardiomyopathy: an under-recognized clinical entity. J Am Coll Cardiol. 2008;52:2175-87.

5. Asimaki A, Tandri $\mathrm{H}$, Huang $\mathrm{H}$, et al. A new diagnostic test for arrhythmogenic right ventricular cardiomyopathy. N Engl J Med. 2009;360:1075-84.

6. Norman M, Simpson M, Mogensen J, et al. Novel mutation in desmoplakin causes arrhythmogenic left ventricular cardiomyopathy. Circulation. 2005;112:636-42.

7. Cox MGPJ, van der Zwaag PA, van der Werf $\mathrm{C}$, et al. ARVD/C: pathogenic desmosome mutations in index-patients predict outcome of family screening. Circulation. 2011;123:2690-700.

8. Merner ND, Hodgkinson KA, Haywood AFM, et al. Arrhythmogenic right ventricular cardiomyopathy type 5 is a fully penetrant, lethal arrhythmic disorder caused by a missense mutation in the TMEM43 gene. Am J Hum Genet. 2008;82:809-21.

9. Maclennan DH, Kranias EG. Phospholamban: a crucial regulator of cardiac contractility. Nat Rev Mol Cell Biol. 2003;4:566-77.

10. van der Zwaag PA, van Rijsingen IA, Asimaki A, et al. Phospholamban R14del mutation in patients diagnosed with dilated cardiomyopathy or arrhythmogenic right ventricular cardiomyopathy: evidence supporting the concept of arrhythmogenic cardiomyopathy. Eur J Heart Fail. 2012;14:1199-207.

11. van der Zwaag PA, van Rijsingen IA, de Ruiter R, et al. Recurrent and founder mutations in the Netherlands - Phospholamban p.Arg14del mutation causes arrhythmogenic cadiomyopathy. Neth Heart J 2013. doi:10.1007/s12471-013-0401-3.

12. van Tintelen JP, Wilde AAM, Jongbloed JDH. Recurrent and founder mutations in inherited cardiac diseases in the Netherlands. Neth Heart J. 2009; 17:407-8.

13. Cerrone M, Noorman M, Lin X, et al. Sodium current deficit and arrhythmogenesis in a murine model of plakophilin-2 haploinsufficiency. Cardiovasc Res. 2012;95:460-80. 